13. Giorgi JV, Cosimi AB, Colvin RB, Goldstein G, Delmonico FL, Russell PS. Monitoring immunosuppression following renal transplantation. Diagn Immunol $1983 ; 1: 174-8$

14. Cosimi AB, Colvin RB, Burton RC, et al. Use of monoclonal antibodies to $\mathrm{T}$-cell subsets for immunologic monitoring and treatment in recipients of renal allografts. N Engl J Med 1981; 305:308-14.

15. Cosimi AB, Burton RC, Colvin RB, et al. Treatment of acute renal allograft rejection with OKT3 monoclonal antibody. Transplantation 1981; 32: 535-9.

16. Burton RC, Cosimi AB, Colvin RB, et al. Monoclonal antibodies to human $T$ cell subsets: use for immunological monitoring and immunosuppression in renal transplantation. J Clin Immunol 1982; 2(3:Suppl):142S$7 \mathrm{~S}$.

17. Silberman H. Dosage of corticosteroids in renal allograft rejection. Am J Surg 1981; 142:413-5

18. Dupont E, Wybran J, Toussaint C. Glucocorticosteroids and organ transplantation. Transplantation 1984; 37:331-5.

19. Fisher RA. Statistical methods for research workers. 14th ed. New York: Hafner, 1973:96-9.

20. Wilcoxon F, Wilcox RA. Some rapid approximate statistical procedures. Pearl River, N.Y.: Lederle Laboratories, 1964:7-9.

21. Mantel N. Chi-square tests with one degree of freedom, extensions of the Mantel-Haenszel procedure. J Am Stat Assoc 1963; 58:690-700.
22. Mantel N, Haenszel W. Statistical aspects of the analysis of data from retrospective studies of disease. JNCI 1959; 22:719-48.

23. Breslow N. A generalized Kruskal-Wallis test for comparing $K$ samples subject to unequal patterns of censorship. Biometrika 1970; 57:579-94.

24. Miller RA, Maloney DG, McKillop J, Levy R. In vivo effects of murine hybridoma monoclonal antibody in a patient with T-cell leukemia. Blood $1981 ; 58: 78-86$

25. Thurlow PJ, Lovering E, d'Apice AJF, McKenzie IFC. A monoclonal antipan-T-cell antibody: in vitro and in vivo studies. Transplantation 1983; 36:293-8

26. Takahashi H, Okazaki H, Terasaki PI, et al. Reversal of transplant rejection by monoclonal antiblast antibody. Lancet $1983 ; 2: 1155-8$

27. Kirkman RL, Araujo JL, Busch GJ, et al. Treatment of acute renal allograft rejection with monoclonal anti-T12 antibody. Transplantation 1983; 36: 620-6.

28. Jaffers GJ, Colvin RB, Cosimi AB, et al. The human immune response to murine OKT3 monoclonal antibody. Transplant Proc 1983; 15:646-8.

29. Chatenoud L, Baudrihaye MF, Chkoff N, Kreis H, Bach JF. Immunologic follow-up of renal allograft recipients treated prophylactically by OKT3 alone. Transplant Proc 1983; 15:643-5.

30. Chatenoud L, Baudrihaye MF, Kreis H, et al. Diversity of the immunization against the monoclonal antibody OKT3 in renal allograft recipients. Transplant Proc (in press).

\title{
EMERGENCY CORONARY ANGIOPLASTY IN REFRACTORY UNSTABLE ANGINA
}

Pim J. de Feyter, M.D., Patrick W. Serruys, M.D., Marcel van den Brand, M.D., Kulasekaram Balakumaran, Bahamshir Moghtar, M.D., Alan L. Soward, M.D., Alf E.R. Arnold, M.D., and Paul G. Hugenholtz, M.D.

\begin{abstract}
We performed percutaneous transluminal coronary angioplasty as an emergency procedure in 60 patients with unstable angina pectoris that was refractory to treatment with maximally tolerated doses of beta-blockers, calcium antagonists, and intravenous nitroglycerin. The initial success rate for angioplasty was 93 per cent (56 patients). There were no deaths related to the procedure, although total occlusion occurred in four patients. Despite emergency bypass grafting, all four sustained a myocardial infarction.
\end{abstract}

All the patients were followed for at least six months. Late cardiac death occurred in one patient, whereas eight had recurrent angina pectoris. There was no progression

$\mathrm{T}$ HE clinical syndrome of unstable angina causes great concern to clinicians because of the perceived high risk of progression to myocardial infarction or cardiac death. ${ }^{1-6}$ Given the heterogeneous coronary pathoanatomy, the variations in time and severity of clinical presentation among patients with unstable angina, and uncertainty about the extent of threatened or actual necrosis of the myocardium, it is unlikely that any one therapeutic approach will be appropriate for all such patients. The various options among pharmacologic treatments and surgery have led to a consensus. ${ }^{3-6}$ It is now common practice to stabilize the acute ischemic symptoms initially with intensive medical treatment and to reserve bypass surgery for patients refractory to such treatment. ${ }^{3-6}$ Since percutaneous transluminal coronary angioplasty has gained acceptance as an alternative form of revascularization, ${ }^{7}$ patients with unstable angina pectoris, al-

From the Thoraxcenter, University Hospital, Erasmus University, Rotterdam, the Netherlands. Address reprint requests to Dr. de Feyter at the Catheterization Laboratory, Thorax Center, BD 414, P.O. Box 1738, 3000 DR Rotterdam, The Netherlands. to myocardial infarction. The restenosis rate was 28 per cent (13 of 46 ) in the patients with initially successful coronary angioplasty who had repeat angiography. Improved cardiac functional status after sustained successful coronary angioplasty was demonstrated by an almost normal capacity on bicycle exercise testing and the absence of ischemia during thallium isotope studies in 80 per cent.

We conclude that emergency percutaneous transluminal coronary angioplasty may be useful for the treatment of selected patients with unstable angina pectoris who are unresponsive to intensive pharmacologic treatment. (N Engl J Med 1985; 313:342-6.)

though initially not thought suitable as candidates because of their instability, have successfully undergone this procedure. ${ }^{8-10}$ Now that investigator experience has grown and important advances have been made in catheter techniques, we considered that it would be timely to review our experience with emergency coronary angioplasty, using a steerable dilatation catheter, as an alternative to coronary artery bypass grafting. The following specific issues were addressed: (1) Can coronary angioplasty relieve ischemic symptoms and prevent progression to myocardial infarction or death in patients not responding to intensive pharmacologic therapy lasting for at least 24 hours? (2) What is the incidence of major complications of the procedure? and (3) What is the rate of recurrence of symptoms or of the occurrence of major cardiac events during at least six months of follow-up?

\section{Methods}

During the period January 1983 to April 1984, 1283 patients were admitted to our coronary care unit. Unstable angina pectoris was diagnosed in 217. The extent of coronary artery disease in these patients is shown in Table 1. In 109 patients the disease was 
refractory to intensification of treatment. Of these, 60 patients with unstable angina pectoris satisfied all the following criteria: (1) chest pain at rest for at least 15 minutes, accompanied by reversible electrocardiographic ST-T changes without such signs of cardiac necrosis as a rise in creatine kinase to twice the normal level or the development of $Q$ waves; (2) hospitalization for at least 24 hours in an intensive care unit, with continuous electrocardiographic and hemodynamic monitoring; (3) optimal medical therapy, including adequate administration of betaadrenergic blockade to achieve a resting pulse of less than 60 beats per minute, nifedipine, and intravenous nitroglycerin to optimize preload (pulmonary capillary wedge pressure $<14 \mathrm{~mm} \mathrm{Hg}$ ) and afterload (systolic aortic pressure $<110 \mathrm{~mm} \mathrm{Hg}$ ) in an effort to increase the coronary blood supply to the jeopardized myocardium; (4) continuation of ischemic attacks, despite such ther-

apy; (5) adequacy of the lesion for surgical intervention or the presence of a coronary artery lesion suitable for treatment by percutaneous transluminal coronary angioplasty (patients were considered suitable for angioplasty if they had localized disease in one vessel and, in case of multivessel disease, if the vessel selected for attempted dilatation did not give off collateral vessels and if left main stem disease was absent); and (6) normal or slightly abnormal left ventricular function.

Sixty patients fulfilled these criteria. Their clinical characteristics are shown in Table 2. The procedure was attempted in 39 patients with a lesion of the left anterior descending artery, 10 with a lesion of the right coronary artery, 10 with a lesion of the circumflex artery, and 1 with a lesion of a graft. In five patients the artery, thought to be technically suitable for angioplasty, was found at the time of angioplasty to be totally occluded; in two patients the artery was already totally occluded at the time of the diagnostic angiogram. The mean ( \pm S.D.) time from admission to angiography was $2.7 \pm 3.6$ days, and from angiography to angioplasty, $3.6 \pm 5.6$ days Coronary angioplasty was performed in 32 patients ( 53 per cent) during normal working hours and in 28 (47 per cent) at night or during the weekend.

The procedure was performed according to the technique of Grüntzig, ${ }^{7}$ with a steerable balloon catheter manufactured either by Schneider-Grüntzig (Zürich, Switzerland) or by Meditech (Watertown, Mass.) inserted by a femoral route. Before the procedure, 250 $\mathrm{mg}$ of aspirin dissolved in $5 \mathrm{ml}$ of normal saline and $100 \mathrm{mg}$ of intravenous heparin were given; during the procedure a continuous drip of low-molecular-weight dextran was given. A Zucker pacing electrode was positioned in the right ventricle. To prevent coronary artery spasm, nifedipine $(0.2 \mathrm{mg})$ or nitroglycerin (isosorbide dinitrate, 1 to $3 \mathrm{mg}$ ) was given into the coronary artery, and this was epeated when necessary. ${ }^{11}$ Only the ischemia-related coronary lesion was dilated in cases in which multivessel disease was present. The ischemia-related lesion was determined by localizing the recorded electrocardiographic changes. Electrocardiographic changes in leads $\mathrm{V}_{1}$ to $\mathrm{V}_{5}$ were associated with lesions of the left anterior descending artery; changes in $\mathrm{I}, \mathrm{aVL}$, and $\mathrm{V}_{6}$, with the marginal branch of the circumflex artery or the diagonal branch of the left anterior descending artery; changes in inferior leads, with either the right coronary artery or the circumflex artery. The transstenotic pressure gradient was measured before and after each dilation. The inflation pressure varied from 2 to $12 \mathrm{~atm}$ for a period of 10 to 60 seconds; on the average the pressure applied was $9.8 \pm 1.8 \mathrm{~atm}$, for a total period per dilation of $218 \pm 111$ seconds.

An angioplasty procedure was considered successful when it reulted in clinical relief of acute ischemic symptoms, with a reduction $n$ the size of the lesion to less than 50 per cent of the luminal iameter or a reduction of the transstenotic pressure gradient to less than 0.30 (the pressure gradient normalized for mean aortic pressure).$^{12}$

After the procedure, all the patients were monitored for 24 hours in the coronary care unit, where electrocardiography was performed and enzyme levels were measured. The patients were usually discharged three days after the procedure. They continued to receive treatment with nifedipine (40 to $60 \mathrm{mg}$ daily) and aspirin (500 mg daily) for six months, with the aim of preventing spasm or platelet aggregation. During the procedure a surgical team was available in case of need. A perioperative myocardial infarction was diagnosed when a new $Q$ wave developed in the 12-lead electrocardiogram.

Clinical follow-up information was obtained at 3,6 , and 12 months, either during a visit by the patient to the outpatient clinic or from the referring physician. Cardiac deaths, myocardial infarctions, and recurrences of angina pectoris were tabulated. The majority of patients underwent an exercise test with thallium scintigraphy and repeat angiography. The patients performed symptom-limited exercise on the bicycle, with stepwise increments in load of $20 \mathrm{~W}$ every minute. The three orthogonal leads $\mathrm{X}, \mathrm{Y}, \mathrm{Z}$ of the Frank lead system were recorded and analyzed. A horizontal STwave depression of $0.1 \mathrm{mV}$ or more during exercise was considered a positive response.

Exercise thallium scintigraphic imaging was performed in the anterior and left anterior oblique $45^{\circ}$ and $65^{\circ}$ views, immediately after injection of $1.5 \mathrm{mCi}$ of thallium-201 at peak stress. The redistribution images were obtained four hours later. Images were obtained with a gamma camera (Searle Radiographics, Des Plaines, Ill.) and processed with a computer interface as previously described. ${ }^{13}$ Defects with redistribution were considered to represent exercise-induced ischemia. Persistent defects without redistribution were considered to represent scars. Repeat angiograms were obtained in multiple views, including hemiaxial angulation, and were interpreted by observers without knowledge of the patient's clinical status. Restenosis was defined as an increase in narrowing of the luminal diameter of the dilated lesion to more than 50 per cent. The severity of the stenosis before and after angioplasty and at control was calculated with the help of a computer-based system for coronary angiography analysis. ${ }^{14}$ Data are expressed as means \pm S.D.

\section{Results}

Percutaneous transluminal coronary angioplasty was initially successful in 56 of the 60 patients (93 per cent). The initial success rate in patients with a totally occluded vessel was 86 per cent (six of seven patients). The mean gradient before coronary angioplasty was $61 \pm 13 \mathrm{~mm} \mathrm{Hg}$; after the procedure it was $18 \pm 12 \mathrm{~mm}$ $\mathrm{Hg}$. The diameter stenosis before angioplasty was $69 \pm 13$ per cent; after successful angioplasty it was $28 \pm 10$ per cent. The success rate for the left anterior descending artery was 95 per cent ( 37 of 39 patients), for the right coronary artery 90 per cent (9 of 10), for 
Table 2. Clinical Characteristics of 60 Patients with Unstable Angina Pectoris and Emergency Percutaneous Transluminal Coronary Angioplasty.

\begin{tabular}{lc}
\hline \hline Characteristics & No. $(\%)$ \\
Male sex & $51(85)$ \\
Mean age (yr) & $59($ range, 36-73) \\
Previous coronary bypass grafting & $5(8)$ \\
Previous myocardial infarction & $23(38)$ \\
New onset of angina pectoris at rest & $29(48)$ \\
Worsening of preexisting stable angina & $20(33)$ \\
Angina within 4 wk after myocardial & $11(18)$ \\
$\quad$ infarction & \\
Left ventricular ejection fraction (mean \pm S.D.) & $0.60 \pm 0.09$ \\
\hline
\end{tabular}

the left circumflex artery 90 per cent (9 of 10), and for the bypass 100 per cent ( 1 of 1 ). In four patients the procedure was complicated by total occlusion of the vessel; all four had a myocardial infarction (pathologic $Q$ waves developed in three, and one had a marked rise in the creatine kinase level) despite emergency coronary artery bypass grafting. There were no deaths related to the procedure.

All the patients were followed for at least 6 months after successful angioplasty, half of them for 12 months (Table 3). One patient died from a myocardial infarction. Seven patients had recurrent angina, all within six months after angioplasty; six were treated either by repeat angioplasty or by bypass grafting. The four patients with unsuccessful coronary angioplasty and emergency bypass surgery were all followed for 12 months; one had a recurrence of angina pectoris.

Table 4 shows the exercise-test data for the 49 patients with successful angioplasty and an uneventful course during follow-up. Electrocardiographic exercise test results were available in 96 per cent ( 47 of 49 ), and thallium scintigraphy results in 86 per cent (42 of 49). The stress tests were performed a mean of $2.1 \pm 1.7$ months after the procedure. The exercise capacity was virtually normal in all the patients. Although they were free of symptoms, 9 per cent ( 4 of 47) had ischemic ST depression, and 19 per cent (8 of 42) had reversible perfusion defects. There were no differences between patients with single-vessel and those with multivessel disease. A repeat angiogram was available in 9 of the 10 patients with a positive stress test (ST-segment depression or reversible perfusion defect or both). The restenosis rate in these

Table 3. Late Results after Initially Successful Percutaneous Transluminal Coronary Angioplasty (PTCA) in 56 Patients with Refractory Unstable Angina.

\begin{tabular}{lccc}
\hline \hline & \multicolumn{3}{c}{ Follow-up Period } \\
& 3 мо & 6 мо & 12 мо \\
No. of patients & 56 & 55 & 27 \\
Death & 1 & 0 & 0 \\
Nonfatal myocardial infarction & 0 & 0 & 0 \\
Recurrence of angina pectoris & 5 & 2 & 0 \\
Repeat PTCA & 1 & 1 & 0 \\
Coronary bypass grafting & 3 & 1 & 0 \\
Medical treatment & 1 & 0 & 0 \\
\hline
\end{tabular}

asymptomatic patients was 33 per cent (three of nine patients), whereas two other patients later became symptomatic and then had restenosis.

Repeat angiograms were available in 46 of the 56 patients (82 per cent) who had an initially successful angioplasty. In 10 patients, angiography was not repeated; one had recurrent angina, eight were free of symptoms, and one had a fatal myocardial infarction. The angiography was performed $2.3 \pm 1.8$ months after coronary angioplasty.

Restenosis occurred in 13 patients (28 per cent), of whom 7 were free of symptoms. All six patients with recurrent angina pectoris had restenosis. On repeat angiography, the diameter stenosis in asymptomatic patients was $34 \pm 18$ per cent; in the symptomatic patients it was $68 \pm 8$ per cent.

\section{Discussion}

The management of unstable angina pectoris is first of all directed toward the relief of acute ischemic symptoms and secondly to the prevention of progression to myocardial infarction. ${ }^{4-6}$ Unstable angina is nearly always associated with high-grade, fixed coronary narrowing, ${ }^{15-17}$ leading to restricted antegrade flow. Other factors, such as generalized increased vasomotor tone, severe localized spasm of the healthy wall in eccentric lesions, or platelet deposition progressing to complete thrombosis, also have a role. ${ }^{18-22}$ Pharmacologic treatment therefore aims either to decrease the myocardial demand for oxygen by reducing the heart rate (bed rest, beta-blockers), adjusting preload and afterload pressures (nitrates, calcium antagonists), and protecting the stunned myocardium (calcium antagonists with beta-blockers), or to increase the oxygen supply more directly by coronary vasodilation (calcium antagonists, nitrates), or by the inhibition of platelet deposition and thrombus formation (aspirin). Although the conditions of most patients will stabilize with optimal medical treatment, consisting of hospitalization and a combination of beta-blockade, calcium antagonists, and intravenous nitroglycerin ${ }^{18,23-26}$ adjusted during continuous electrocardiographic and hemodynamic monitoring and administered in maximally tolerated doses, a subgroup of patients will continue to have pain and presumably ischemia. Previous studies have indicated that high rates of mortality and cardiac events occur in this subset of patients. ${ }^{3,4,23-26}$ Coronary artery bypass grafting has been suggested as the treatment of choice.

Percutaneous transluminal coronary angioplasty has been shown to improve coronary blood flow by reducing the severity of the obstruction in selected patients with stable angina pectoris. ${ }^{7}$ Therefore, the rationale for its use in patients who do not respond to medical treatment lies in its potential to provide revascularization of the jeopardized myocardium without the need for coronary bypass surgery, with its attendant risks of perioperative myocardial infarction or death. ${ }^{27}$ However, coronary angioplasty often causes 
vasospasm in patients with stable angina, and if vasospasm is a frequent and important factor in unstable angina, then intracoronary instrumentation may be unduly hazardous. The study by Williams et al ${ }^{8}$ and more recently those by Meyer et al. ${ }^{9}$ and Faxon et al. ${ }^{10}$ have shown that coronary angioplasty could be performed safely and successfully in unstable angina.

The patients who underwent emergency coronary angioplasty in our study constitute a small subgroup of the large spectrum of patients with unstable angina. Our selection process required that the patients had to be refractory to intensive medical therapy after at least 24 hours of hospitalization and to have coronary lesions technically suitable for bypass surgery. From this group were ultimately selected for emergency coronary angioplasty those who had a lesion of the ischemia-related vessel suitable for the procedure, no left main stem disease, and a normal or only slightly abnormal left ventricular function.

In our study, coronary angioplasty was successful in 93 per cent of the patients in whom the procedure was attempted. This success rate is higher than the 61 to 76 per cent reported by the three studies cited above but is comparable to the 85 to 90 per cent reported in series of patients with stable angina pectoris. ${ }^{28-30} \mathrm{It}$ should be emphasized here that the procedure in our study was performed with a steerable dilatation catheter, which has been shown to increase the initial success rate to 10 per cent above that achieved with a nonsteerable dilatation catheter, as was used in the other studies. The National Heart, Lung, and Blood Institute's percutaneous transluminal coronary angioplasty registry ${ }^{30}$ reported that acute coronary events associated with coronary angioplasty occurred more frequently in patients with unstable angina.

In our study the procedure resulted in progression to coronary artery occlusion in four patients ( 7 per cent). In two patients the vessel became occluded during the attempts to cross the lesion, apparently because of damage to the vessel by the guide wire at the site of the lesion. In two patients the dilation resulted in dissection with total occlusion. These patients were promptly revascularized with bypass grafting, yet all had a myocardial infarction. Although the prognosis for such patients with coronary bypass surgery is uncertain, we believe that these cases show again that immediate surgical standby remains a requirement to ensure patient safety. There were no deaths related to the coronary angioplasty procedure. These results compare favorably with the complication rates for hospital mortality and myocardial infarction of 0.9 and 9 per cent, respectively, reported by the National Heart, Lung, and Blood Institute's percutaneous transluminal coronary angioplasty registry. ${ }^{10}$

During a follow-up of at least six months after successful coronary angioplasty, there was clinical progression of the disease in 8 of 56 patients ( 14 per cent), with fatal myocardial infarction in 1 patient ( 2 per cent) and recurrence of angina pectoris in 7 (13 per cent). The patient who died was free of symptoms for
Table 4. Exercise Electrocardiographic Testing and Thallium Scintigraphy after Successful Percutaneous Transluminal Coronary Angioplasty and Uneventful Follow-up in 47 Patients.

\begin{tabular}{|c|c|c|c|c|}
\hline $\begin{array}{c}\text { EXTENT OF } \\
\text { CAD* }\end{array}$ & $\begin{array}{l}\text { No. of } \\
\text { Patients }\end{array}$ & $\begin{array}{c}\text { EXercise Capacity } \\
(\% \text { OF Normal Value }) \dagger\end{array}$ & $\begin{array}{c}\text { ST-SEGMENT } \\
\text { DEPRESSION } \\
\geqslant 1 \mathrm{MM}\end{array}$ & $\begin{array}{c}\text { Thallium- } \\
\text { Reversible } \\
\text { Perfusion } \\
\text { Defect } \ddagger\end{array}$ \\
\hline & & & \multicolumn{2}{|c|}{ no. of patients (\%) } \\
\hline $\begin{array}{l}\text { One-vessel } \\
\text { disease }\end{array}$ & 34 & $99 \pm 17$ & $2(6)$ & $6 / 30(20)$ \\
\hline $\begin{array}{c}\text { Multivessel } \\
\text { disease§ }\end{array}$ & 13 & $93 \pm 15$ & $2(15)$ & $2 / 12(17)$ \\
\hline Total & 47 & $97 \pm 16$ & $4(9)$ & $8 / 42$ (19) \\
\hline
\end{tabular}

*CAD denotes coronary artery disease.

$†$ Values are expressed as means \pm S.D

$\ddagger$ Thallium scintigraphy data were available for only 42 patients.

§Includes patients with multivessel disease in whom only the ischemia-related vessel was dilated.

one week after the procedure and died after recurrent infarction. At autopsy the initially successfully dilated lesion was totally occluded by a fresh thrombus. The recurrence of symptoms after dilation was corroborated by an angiographically determined restenosis in all symptomatic patients. The angiographic restenosis rate was 28 per cent (including 10 per cent that were asymptomatic). This rate is similar to that reported in stable angina pectoris (20 to 30 per cent $)^{7}$ and unstable angina pectoris (22 per cent).$^{9}$

The results of electrocardiographic exercise testing and thallium scintigraphy indicated that in asymptomatic patients after percutaneous transluminal coronary angioplasty, the exercise capacity became virtually normal, although there was an 8 per cent incidence of an abnormal electrocardiographic response and a 19 per cent incidence of reversible perfusion defects. These abnormal responses occurred to the same extent in patients with one-vessel disease as in patients with multivessel disease in whom only the ischemiarelated vessel was dilated. These results support our opinion that angioplasty of the ischemia-related vessel in patients with multivessel disease with refractory unstable angina pectoris is an attractive approach, at least for the short term.

Thus, at an acceptable risk and with a high initial success rate, percutaneous transluminal coronary angioplasty can restore coronary blood flow in refractory unstable angina, although these results must compete with those of emergency coronary artery bypass grafting. A recent nonrandomized study ${ }^{10}$ compared the rates of myocardial infarction and death in a comparable group of patients with one-vessel disease and unstable angina pectoris who underwent either coronary bypass surgery or coronary angioplasty. From these data it appears that angioplasty compares favorably with bypass surgery. The procedure is associated with similar mortality and morbidity rates, but a more marked improvement in symptoms can be expected after coronary angioplasty. Unfortunately, the data available from that study do not contain information about patients with refractory unstable angina, but 
support our opinion that percutaneous transluminal coronary angioplasty, as an emergency procedure in selected patients with unstable angina refractory to medical treatment, is very efficacious.

We are indebted to Gusta Koster for assistance in the preparation of the manuscript.

\section{REFERENCES}

1. Cairns JA, Fantus IG, Klassen GA. Unstable angina pectoris. Am Heart J 1976; 92:373-86.

2. Scanlon PJ. The intermediate coronary syndrome. Prog Cardiovasc Dis $1981 ; 23: 351-64$.

3. Russell RO Jr, Moraski RE, Kouchoukos N, et al. Unstable angina pectoris: National Cooperative Study Group to Compare Surgical and Medical Therapy. II. In-hospital experience and initial follow-up results in patients with one, two and three vessel disease. Am J Cardiol 1978; 42:839-48.

4. Plotnick GD. Approach to the management of unstable angina. Am Heart J 1979; 98:243-55.

5. Silverman KJ, Grossman W. Angina pectoris: natural history and strategies for evaluation and management. N Engl J Med 1984; 310:1712-7.

6. Michels R, Hugenholtz PG, Haalebos M, van den Brand M, Serruys PW Balakumaran K. Management of unstable angina pectoris. In: Adelman AG, Goldman BS, eds. Unstable angina - recognition and management. Littleton, Mass.: PSG, 1981:143-63.

7. Grüntzig AR, Senning A, Siegenthaler WE. Nonoperative dilatation of coronary-artery stenosis: percutaneous transluminal coronary angioplasty. N Engl J Med 1979; 301:61-7.

8. Williams DO, Riley RS, Singh AK, Gewirtz H, Most AS. Evaluation of the role of coronary angioplasty in patients with unstable angina pectoris. Am Heart J 1981; 102:1-9.

9. Meyer J, Schmitz H-J, Kiesslich T, et al. Percutaneous transluminal coronary angioplasty in patients with stable and unstable angina pectoris: analysis of early and late results. Am Heart J 1983; 106:973-80.

10. Faxon DP, Detre KM, McGabe $\mathrm{CH}$, et al. Role of percutaneous transluminal coronary angioplasty in the treatment of unstable angina: report from the National Heart, Lung, and Blood Institute Percutaneous Transluminal Coronary Angioplasty and Coronary Artery Surgery Study Registries. Am J Cardiol 1983; 53(12):131C-5C.

11. Serruys PW, van den Brand M, Brower RW, Hugenholtz PG. Regional cardioplegia and cardioprotection during transluminal angioplasty, which role for nifedipine? Eur Heart J 1983; 4: (Suppl C):115.

12. Wijns W, Serruys PW, Reiber JHC, et al. Quantitative angiography of the left anterior descending coronary artery: correlations with pressure gradien and results of exercise thallium scintigraphy. Circulation 1985; 71:273-9.

13. Reiber JHC, Lie SP, Simoons ML, Wijns W, Gerbrands JJ. Computer quantification of location, extent and type of thallium 201 myocardial perfusion abnormalities. IEEE $1982 ; 82: 123-8$.
14. Serruys PW, Reiber JHC, Wijns W, et al. Assessment of percutaneous transluminal coronary angioplasty by quantitative coronary angiography: diameter versus densitometric area measurements. Am J Cardiol 1984; 54:482-8.

15. Alison HW, Russell RO Jr, Mantle JA, Kouchoukos NT, Moraski RE, Rackley CE. Coronary anatomy and arteriography in patients with unstable angina pectoris. Am J Cardiol 1978; 41:204-9.

16. McMahon MM, Brown BG, Cukingnan R, et al. Quantitative coronary angiography: measurements of the "critical" stenosis in patients with unstable angina and single-vessel disease without collaterals. Circulation 1979; 60:106-13.

17. Rafflenbeul W, Smith LR, Rogers WJ, Mantle JA, Rackley CE, Russell RO Jr. Quantitative coronary arteriography: coronary anatomy of patients with unstable angina pectoris reexamined 1 year after optimal medical therapy. Am J Cardiol 1979; 43:699-707.

18. Hugenholtz PG, Michels HR, Serruys PW, Brower RW. Nifedipine in the treatment of unstable angina, coronary spasm and myocardial ischemia. Am J Cardiol 1981; 47:163-73.

19. Maseri A, L'Abbate A, Baroldi G, et al. Coronary vasospasm as a possible cause of myocardial infarction: a conclusion derived from the study of "preinfarction" angina. N Engl J Med 1978; 299:1271-7.

20. Epstein SE, Talbot TL. Dynamic coronary tone in precipitation, exacerbation and relief of angina pectoris. Am J Cardiol 1981; 48:797-803.

21. Serruys PW, Steward R, Booman F, Michels R, Reiber JHC, Hugenholtz PG. Can unstable angina pectoris be due to increased coronary vasomotor tone? Eur Heart J 1980; 1:(Suppl B):71-85.

22. Mandelkorn JB, Wolf NM, Singh $\mathrm{S}$, et al. Intracoronary thrombus in nontransmural myocardial infarction and in unstable angina pectoris. Am J Cardiol 1983; 52:1-6.

23. Moses JW, Wertheimer JH, Bodenheimer MM, Banka VS, Feldman M, Helfant RH. Efficacy of nifedipine in rest angina refractory to propanolol and nitrates in patients with obstructive coronary artery disease. Ann Intern Med 1981; 94:425-9.

24. Gerstenblith G, Ouyang P, Achuff SC, et al. Nifedipine in unstable angina. A double-blind, randomized trial. N Engl J Med 1982; 306:885-9.

25. Blaustein AS, Heller GV, Kolman BS. Adjunctive nifedipine therapy in high-risk, medically refractory, unstable angina pectoris. Am J Cardiol 1983; 52:950-4.

26. Kaplan K, Davison R, Parker M, Przybylek J, Teagarden JR, Lesch M. Intravenous nitroglycerin for the treatment of angina at rest unresponsive to standard nitrate therapy. Am J Cardiol 1983; 51:694-8.

27. Kennedy JW, Kaiser GC, Fisher LD, et al. Clinical and angiographic predictors of operative mortality from the Collaborative Study in Coronary Artery Surgery (CASS). Circulation 1981; 63:793-802.

28. Cowley MJ, Block PC. Percutaneous transluminal coronary angioplasty. Mod Concepts 1981; 50:25-9.

29. Meier B, Grüntzig AR, King SB III, et al. Higher balloon dilatation pressure in coronary angioplasty. Am Heart J 1984; 107:619-22.

30. Dorros G, Cowley MJ, Simpson J, et al. Percutaneous transluminal coronary angioplasty: report of complications from the National Heart, Lung, and Blood Institute PTCA Registry. Circulation 1983; 67:723-30. 